\title{
ANTONIO MARÍA ANTONOZI, INGENIERO DE LAS COMEDIAS DEL BUEN RETIRO (1657-1662). NUEVOS DATOS PARA LA BIOGRAFÍA DE UN INVENTOR DE 'MARAVILLOSAS APARIENCIAS'
}

\author{
POR \\ JuAn RAmón SÁNChez del Peral y LóPEZ \\ Museo Nacional del Prado
}

El presente artículo pretende cubrir la laguna documental que hasta hoy constituía la biografía del escenógrafo italiano Antonio María Antonozi, figura relegada al olvido en la historiografía española, a pesar de que jugó un importante papel en la dirección de las comedias del Real Sitio del Buen Retiro, en Madrid, en los años finales del reinado de Felipe IV. Al mismo tiempo, se ha pretendido precisar algunas cuestiones de fondo erróneamente planteadas hasta ahora y esclarecidas en el presente artículo sobre la participación de los pintores de corte en las puestas en escena teatrales.

Palabras clave: Antonio Ma Antonozi; Cosme Lotti; Baccio del Bianco; Escenografía; Buen Retiro.

The author attempts to cover the documentary lacuna, which until now constituted the biography of the Italian scenographer Antonio María Antonozi, a forgotten figure in Spanish historiography, in spite of having played an important role directing comedies in the Real Sitio del Buen Retiro (Madrid) during the final years of the reign of Felipe IV. Likewise, an attempt is made to clarify certain basic questions heretofore incorrectly proposed, but explained in this article, concerning the participation of Court painters in the elaboration of theatrical scenography.

Key words: Antonio Ma Antonozi; Cosme Lotti; Baccio del Bianco; Scenography; Buen Retiro.

"El aparato de mutaciones y tramoyas, fue de tan maravillosas apariencias,
que pudiera dar embidia en Italia, de cuyos Teatros encarece tanto la fama"
Luis de Ulloa y Pereira, Fiestas que se celebraron en la Corte
por el nacimiento de Don Felipe Próspero, Príncipe de Asturias, 1658.

El interés creciente en los últimos tiempos por la historia de la escenografía en España nos conduce a publicar nuevos documentos que completan la biografía de uno de los escenógrafos italianos que convirtieron las tablas del Salón de Comedias del Buen Retiro en punto de referencia 
de su época. El ingeniero romano Antonio María Antonozi ${ }^{1}$ representa el cambio de rumbo o el punto de inflexión de los montajes teatrales en la corte madrileña, y el final de una línea trazada durante todo el reinado de Felipe IV por figuras como Cosme Lotti y Baccio del Bianco. Pero hasta ahora la personalidad de Antonozi había quedado en la sombra, al desconocerse la práctica totalidad de las circunstancias que rodearon su estancia en Madrid.

Durante todo su reinado, Felipe IV mantuvo una persistente pugna diplomática por conseguir los mejores especialistas que asegurasen el lustre debido a su corte en un intenso afán por disfrazar la realidad del Estado². La falta de tradición firme en la creación de "mutaciones" para comedias en España, hizo necesario volver la vista hacia Italia y a sus representaciones cortesanas, que ya habían desarrollado brillantes montajes teatrales sustentados básicamente sobre las transformaciones escénicas más innovadoras y atractivas. Neumeister describe con precisión la situación general, al decir que:

"La ostentación cortesana hace necesario que los españoles importen de Italia, país preferido de la cultura teatral de la época, no textos o autores de obras dramáticas sino tramoyas, músicas, decorados, efectos. 'Por los escenógrafos italianos empleados en todas las grandes cortes de Europa', escribe el historiador del arte Hans Tintelnot, 'comienza a tener impacto sobre la evolución del barroco un tipo de artista que desempeña un papel cada vez más sustancial para los intercambios entre las artes plásticas y el teatro (...), el pintor-ingeniero, el homo universalis, el artista versado en todos los conocimientos literarios y técnicos" 3 .

Así, la presencia de los ingenieros italianos aporta una amplitud de miras que alcanza mucho más allá de la sola representación de una obra literaria, y que supone la integración de muchos aspectos de la cultura barroca sobre la escena, para mayor grandeza de la Monarquía.

Recién inaugurado el reinado de Felipe IV, llegó a la Corte española el napolitano Giulio Cesare Fontana -hijo del arquitecto Domenico Fontana- que introdujo novedosos aspectos escénicos procedentes de la corte medicea de Florencia. Tras esos primeros pasos de la nueva andadura escénica en la corte hispánica llegó el florentino Cosme Lotti, discípulo de Giulio Parigi, quien a su vez lo era de Bernardo Buontalenti, al cual se debe en gran parte la concepción de la escenografía moderna. Lotti se estableció en Madrid en 1626, donde moriría en 1651. Pero, Lotti no ha pasado sólo por los fastos teatrales a los anales de la historia teatral española, sino, sobre todo por haber realizado el diseño del Coliseo del Buen Retiro, construido entre 1638 y 1640 por Alonso Carbonel, Maestro Mayor de las Obras Reales; con él, por fin, el Real Sitio pudo contar con un lugar construido ex profeso para la representación de comedias. Muchos y muy grandes fueron los logros escénicos del italiano hasta la fecha de su muerte. Pero, como el espectáculo siempre debe continuar, también Lotti tuvo su sucesor al frente de la dirección escénica del Coliseo ${ }^{4}$. En un nuevo reto diplomático se buscó al más y mejor dotado de los ingenieros toscanos y el resultado fue la llegada a Madrid de Baccio del Bianco, y con él, el momento álgido de las mutaciones en España.

\footnotetext{
${ }^{1}$ Aunque el apellido en italiano se escribiría Antonozzi, se ha preferido transcribirlo con una sola zeta, equivalente al sonido de la ce con cedilla con la que aparece escrito su nombre (incluida su firma autógrafa) en los documentos españoles.

${ }^{2}$ Sobre estos aspectos, cfr. Neumeister, Sebastian, "Escenografía cortesana y orden estético-político del mundo", en Egido, Aurora (coord.), La escenografía del teatro barroco, Salamanca, 1989, pp. 141-159; NiETO BedoyA, MARTA y Durán Cermeño, Consuelo, "Escenografía, usos y maneras del rey Felipe IV y la Corte en el Real Sitio del Buen Retiro", en Madrid. Revista de arte, geografía e historia, Comunidad de Madrid, no 2 (1999), pp. 171-194.

3 Neumeister, S., op. cit., p. 145.

${ }^{4}$ Hay que señalar que en el breve lapso de tiempo que transcurrió entre la muerte de Lotti y la llegada de Del Bianco, fue FrANCISCO RICCI el encargado de proseguir la labor teatral cortesana; ARRÓNIZ, OTHÓN, La influencia italiana en el nacimiento de la Comedia española, Madrid, 1969, p.267.
} 
De este modo llegamos prácticamente al límite posterior del reinado de Felipe IV, con la repentina muerte de Baccio en 1657 -como dijo el cronista, trasladado seguramente a representar

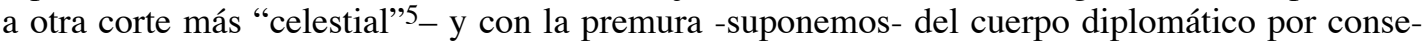
guir un nuevo director teatral que, al igual que sus antecesores, hiciese las delicias del Rey y consiguiese el solaz cortesano en su Buen Retiro.

Pero hasta ahora el último eslabón de la cadena no ha sido valorado, a pesar de ser el que la sostiene -si se permite la metáfora- pues prácticamente se ha pasado por alto que Baccio del Bianco también tuvo un digno sucesor: Antonio María Antonozi. Una vez más un ingeniero italiano se haría cargo del Real Coliseo de Comedias.

Las noticias con las se contaba hasta hoy sobre Antonio María Antonozi han sido escasas y repetitivas. Por ejemplo, se ha supuesto que Antonozi llegó a España de la mano de Giulio Rospigliosi, poeta, nuncio y futuro pontífice Clemente IX, ${ }^{6}$ para cubrir la vacante que había dejado la muerte de Baccio del Bianco en $1657^{7}$, aunque por otra parte se ha a sugerido también que pudo llegar con el ingeniero florentino en diciembre de $1650^{8}$.

El ingeniero "romano" es fácilmente identificable con el "Antonio Romano" que ha mencionado recientemente algún autor" -aunque el susodicho estudioso no haya podido identificarlo-, al analizar la correspondencia entre el diplomático Vieri de Castiglione y el Cardenal Giovan Carlo de' Medici:

"Pocchi giorni sino è morto un tale Antonosi Romano, che successe a Baccio del Bianco nella soprintendenza del Teatro delle Comedie del Buon Ritiro [...]"10.

\footnotetext{
5 Rich Greer, Margaret, "Introducción al teatro cortesano de Calderón”, en Aparicio Maydeu, Javier (ed.), Estudios sobre Calderón, II, Madrid, 2000, pp. 513-575, cita en p. 533: "Un cronista contemporáneo sugiere con una nota de humor que su muerte repentina debía obedecer a una llamada para trabajar en una corte más elevada: 'Bacho el tramoyista, lunes, viniendo desde el Retiro a Madrid, se cayó muerto en el Prado. Debe de ir a hacer a la otra vida alguna comedia para San Juan, pues va tan deprisa' (BARrionuevo Jerónimo de, Avisos (1654-1658) (ed. Paz y Meliá, A., Madrid, 1968), I, p. 286)".

6 "En 1657 había muerto Baccio del Bianco y vino en su sustitución Antonio María Antonozzi, pintor y arquitecto romano que tuvo como introductor en la Corte madrileña al nuncio apostólico Giulio Rospigliosi, un destacado libretista de óperas italianas", Rich GrEeR, M., op. cit. La autora no cita sus fuentes, pero la principal podría ser con seguridad CotARElo y Mori, EMILIO, “Actores famosos del siglo XVII. Sebastián de Prado y su mujer Bernarda Ramírez”, en Boletín de la Real Academia Española, años II-III, tt. II-III (1915-1916), pp.251-293, 425-457 y 1-38, 151-185, cita en t. III (1916), p. 5, nota 1, quien lanzó la hipótesis por primera vez, repetida sin referir tampoco su origen es STEIN, LouISE K., Songs of Mortals, Dialogues of the Gods. Music and theatre in Seventeenth-Century Spain, Oxford, 1993, pp. 124-125; pero sí lo hace SABIK, KAZIMIERZ, El teatro de Corte en España en el ocaso del Siglo de Oro (1670-1700), Varsovia, 1994, cita en p. 32. Stein indica los dos viajes de Giulio Rospigliosi a Madrid, el primero en julio de 1626 en el séquito del Cardenal Francesco Barberini y el segundo, ya como Nuncio apostólico entre 1644 y 1653 . Para el primer viaje, véase Simón Díaz, José, "La estancia del cardenal legado Francisco Barberini en Madrid el año 1626", en Anales del Instituto de Estudios Madrileños, 17 (1980), pp. 159-213. Cita Stein como su principal fuente para este tema -especialmente para lo que respecta al segundo viaje- a Murata, Margaret, Operas for the Papal Court 1631-1668, Ann Arbor, 1981, obra a la que por desgracia no he tenido acceso directo.

${ }^{7}$ Su testamento, fechado el 26 de junio de 1657, fue publicado por Agulló y CoBo, M., Más noticias sobre pintores madrileños de los siglos XVI al XVIII, Madrid, 1981, pp. 28-29.

8 “...[Baccio del Bianco] Era giunto a Madrid nel dicembre 1650 assieme al romano Antonio Antoniozzi...”, Angiolillo, Marialuisa, Le origini della scenografia barocca (1550-1650), Roma, 1997, p. 67. Se debe tomar con reservas dicha información, puesto que la autora no indica cuáles son sus fuentes. Debo esta información a la generosa ayuda de mi querido amigo David García Cueto, quien, en medio de sus andanzas investigadoras por Italia dió con esta referencia que me brinda, como digo.

9 "Una carta del agente toscano Vieri di Castiglione al cardenal Giovan Carlo de' Medici, fechada en Madrid, el 9 de agosto de 1662, informa de la muerte de un tal Antonio Romano, que había sucedido a Baccio del Bianco en la Superintendencia del Teatro de Comedias del Buen Retiro;", Salort Pons, Salvador, Velázquez en Italia, Madrid, 2003, p. 151.

10 (Madrid, 9-agosto-1662) Florencia, Archivio di Stato, Mediceo del Principato, 5384 (s. f.), en Salort Pons, S., ibídem, pp. 151 y $487-488$, doc.b68.
} 
De la respuesta del Cardenal De' Medici al agente toscano puede deducirse que el purpurado sí conocía al ingeniero:

"Signore Cav. Vieri Intendo dalla lettera di VS de questo pasato, che il re mio signore desiderebbe un ingegniere, che potese servir costà al Teatro delle commedie come faccieva Baccio del Bianco, et ultimamente, L'Antonozzi Romano;"11

Según el mismo autor, "Baccio del Bianco -que había sustituido en 1651 a su compatriota Cosimo Lotti- fue reemplazado en la Sobreintendencia del Teatro de las Comedias, en 1657, por Antonio Romano. [...] la documentación manejada parece indicar que Romano ocupó la Sobreintendencia del Teatro desde 1657 a 1662"; en nota aclaratoria añade que "a parte de la fecha de su muerte, no tenemos otras noticias sobre Antonio Romano"12.

Pues bien, según otros autores -que sí tienen alguna otra noticia-, el 27 de febrero de 1658 Antonio María Antonozi había realizado la escenografía para la representación en el Buen Retiro de la obra de Antonio de Solís Triunfos de Amor y Fortuna ${ }^{13}$, en honor del nacimiento del príncipe Felipe Próspero ${ }^{14}$.

Además, el 5 de diciembre de 1658 Antonozi se encargó del montaje de dos de las más célebres obras de Pedro Calderón de la Barca, La púrpura de la rosa y Celos aún del aire matan ${ }^{15}$, los primeros ejemplos de óperas españolas. En el caso de otras comedias representadas ese mismo año en el Retiro no se ha podido hacer otra cosa que suponer la dirección escenográfica del

11 (Florencia, 22-septiembre-1662) Florencia, Archivio di Stato, Mediceo del Principato, 5055 ( $1^{\text {a }}$ parte, s.f.), ibidem, pp. 156,424 , nota 29 y 488 , doc.b69.

12 Ibídem, pp. 151-152 y 423, nota 14

13 Sobre la comedia y su autoría, cfr. SHERgold, N. D. Y VAREY, J. E., Comedias en Madrid 1603-1709. Repertorio y estudio bibliográfico, Madrid, 1989, pp. 232-233.

${ }^{14} \mathrm{Al}$ parecer, ésta obra podría estar preparada antes del nacimiento del Príncipe, cfr. SHERGOLD, N.D., A History of the Spanish Stage from medieval times until the end of the Seventeenth-Century, Oxford, 1967, p. 320. Este autor, cita como fuente primigenia para poner en relación a Antonozi con el montaje de esta comedia, a LEÓN PINELO, ANTONIO DE, Anales de Madrid (desde el año 447 al de 1658), fol. 378, información que también recoge Stein, L. K., op. cit., p. 282. Pero el que citó por primera vez a León Pinelo, fue Cotarelo y Mori, E., cita en t. III (1916), pp. 5-6, nota 1, citado a su vez únicamente en SABIK, K., op. cit., cita en p. 32. También Pedraza contempla la posibilidad de que Antonozi se basase en unos decorados preexistentes, de Baccio, Pedraza JiménEZ, FeliPe B., "El teatro cortesano en el reinado de Felipe IV", en Teatro cortesano en la España de los Austrias, Madrid, 1998, pp. 75-103, cita en p. 94: "El 27 de enero de 1658, para celebrar el nacimiento del príncipe Felipe Próspero, vuelve [Antonio] Solís con Triunfos de amor y fortuna, cuya escenografía pinta Antonio María Antonozzi, quizá, como sugiere Cardona [prol. CALdERón, La púrpura..., p. 119] aprovechando decorados de La fiera... [el rayo y la piedra, obra de Pedro Calderón de la Barca]"; parece que esto se podría confirmar también por medio de unas palabras de Francisco Rizi, quien afirmaba que "en 1655 había comenzado a trabajar en el aderezo del teatro para 'la comedia grande que se había de hacer en el Coliseo y se dejó hasta las Carnestolendas del año de 1658 que se hizo el festejo del nacimiento del Príncipe Nuestro Señor"', cfr. PÉREZ SÁNCHEZ, Alfonso E., "Los pintores escenógrafos en el Madrid del siglo XVII", en EGIDO, A., op. cit., cita en p. 75.

15 Pedraza JimÉnez, F. B. (1998), p. 94: "El cinco de diciembre se representaron en el Retiro La púrpura de la rosa y Celos aun del aire matan, ambas con textos de Calderón y escenografía de Antonio María Antonozzi”. Sabik hace interesantes apreciaciones al respecto de las escenografías de las dos obras in musica de Calderón al añadir que "para la escenificación de esta primera ópera calderoniana [La púrpura de la rosa], Antonozzi utiliza cinco decorados: bosque, gruta, jardines, monte y -finalmente- cielo. Todos ellos como decorados-tipo, son conocidos de la escenografía operística italiana [...] Calderón, sin duda animado por el éxito de la representación de La púrpura de la rosa, sigue el mismo camino y fija el género o, mejor dicho, la fórmula de la comedia lírica española, con su 'fiesta grande cantada' Los celos aún del aire matan, representada -al igual que su antecesora- en el Coliseo del Buen Retiro en diciembre del mismo año 1600. Esta vez el autor presenta como libreto una comedia regular en tres jornadas. El asunto es invariablemente mitológico en este caso se trata de la fábula de Céfalo y Procris, tomada de las Metamorfosis [...] El montaje de la obra se realizó bajo la dirección del marqués de Heliche quien -a partir de 1656- colabora con Calderón en la organización de sus piezas mitológicas", SABIK, K., El Teatro de Corte en España en el ocaso del Siglo de Oro (1670-1700), Varsovia, 1994, pp. 35-36. 
italiano, como en la zarzuela El laurel de Apolo (estrenada en el Buen Retiro el 4 de marzo de $1658^{16}$ ), pero este extremo no ha podido ser documentado de modo efectivo ${ }^{17}$, al igual que sucede con el resto de las comedias de Calderón que se representaron hasta 1662.

También puede detectarse ahora la presencia de Antonozi en cierta documentación ya publicada por Varey y Shergold -aunque no lo hicieran en su día estos autores-, en la que puede hallarse al ingeniero involucrado en el montaje escénico de una comedia en el Buen Retiro en $1660^{18}$.

$\mathrm{Si}$ atendemos a lo publicado por Arróniz -sin referencias documentales concretas-, Antonozi también trabajó como director de escena en la representación, otra obra de Antonio de Solís en el Retiro de Psiquis y Cupido estrenada el día 19 de enero de 166219 . A este respecto, hay que tener en cuenta una fuente, al parecer, no advertida hasta hoy, sobre el nacimiento del príncipe Felipe Próspero. Si bien, no contribuye -a primera vista, al menos- a esclarecer lo anteriormente apuntado aquí, parece sin embargo, testimonio muy digno de considerar, aunque crea cierta contradicción con las afirmaciones de otros contemporáneos del evento, como León Pinelo. La crónica de Méndez de Silva incluye una expresiva descripción de los festejos que acompañaron al feliz nacimiento en la que se hace expresa la participación de Antonozi ${ }^{20}$.

Angiolillo afirma además que "lavorò ad apparati per spettacoli all'aperto su carri" 21 y es de suponer que se refiere al diseño o montaje de los carros de una de las procesiones del Corpus

16 Cotarelo y Mori, Emilio, Ensayo sobre la vida y obras de don Pedro Calderón de la Barca, Madrid, 1924 (edic. facs. Madrid, 2001, p. 307).

17 SABIK, K., op. cit., p. 32: "Se puede suponer que el autor de la escenografía de El laurel de Apolo [zarzuela de Calderón representada en 1658 en el Coliseo del Buen Retiro] fue Antonio María Antonozzi, un pintor y arquitecto romano traído a Madrid gracias a Rospigliosi. Es él quien sucede a Baccio del Bianco como escenógrafo del teatro de Corte madrileño a la muerte de éste en 1657.”, citando a COTARELO Y MORI, E., t. II (1915), p. 620.

18 Shergold, N. D. y VAREY, J.E., Representaciones palaciegas: 1603-1699. Estudio y documentos, Madrid, 1982. En p. 60, documento $\mathrm{n}^{\circ} 25$, puede leerse:

"1660. Sobre cera para una comedia. // Sin fecha. Memoria de las belas y achas para el teatro del miércoles: // 78 belas para el frontispicio..... 78 // Apuntadores 4 // .... // 82.... // 16 anchas para los bastidores y el foro.....16 // Esto se ha de entregar a don Antonio María [...]"

19 ArRónIZ, O., op. cit., p. 267 y ShERGOLd, N.D. y VAREY, J.E., op. cit., 1989, pp. 194-195.

20 "Miercoles siguiente 27 [de febrero de 1658] se representó a Sus Magestades, y Alteças en el Real Coliseo del mismo Retiro, la mas portentosa comedia que se ha visto en Europa, de las dos fábulas, Psichis y Cupido, Endimion y la Luna, a donde luziò el raro talento de su Autor D. Antonio de Solis, Secretario del Rey, y Oficial de Estado; pues les adornò con prodigiosa traça, sentencias graves, vozes misteriosas, agudamente colocadas, versos gallardos, profundos y eloquentes, de cuya verdad mejor que yo, informaran ellos mismos; pagando todos los oyentes (aun los mas reportados en alabar agenas gracias) el gusto que avian tenido, con parabienes cortesanos. Por otra parte Don Antonio María Antonozzi, Romano, celebre ingeniero de nuestro siglo, adelantando maravillosamente el Arte de los famosos Cosmelot y Bacche Bianco, Florentinos, bien conocidos en España; ostentò su rara capacidad, en la disposición de innumerables tramoyas; mudandose a la luz de infinitos faroles, tantas vezes el teatro en diversas perspectivas, y peregrinos aparatos de bien imitado Cielo, Sol, Luna y Estrellas, ligeras nubes, fingidos mares, vistosos baxeles, encumbradas peñas, frondosos bosques, floridos prados, cristalinas fuentes, notables edificios, ricos palacios, deliciosos jardines, y transformaciones increibles de figuras diferentes, que en instantaneos buelos, artificiosos bayles, suaves musicas y gustosos entremeses, pusieron el Non Plus Vltra a la admiracion. El Viernes I de Março, como también el Sabado, se representó a los Consejos, Reynos juntos en Cortes y Villa de Madrid, empeçandose a las 4 de la tarde, se acabó a las 9 de la noche. Ultimamente continuandose en los dias siguientes de Carnestolendas varias Comedias y festines, dispuestos como todos los passados por el incomparable desvelo y curiosa atencion del Ex ${ }^{c m o}$ Marques de Heliche a quien meritissimamente se deven los aplausos de tan magestuosas y alegres demostraciones; fueron el miercoles Sus Magestades y Alteças a Palacio, por ocasión de la Quaresma, para bolver a celebrar en la Pasqua con mayores regozijos, la felicidad mas gloriosa desta Catolica Monarquia, que ha tenido en el Nacimiento de su deseado Príncipe Don Felipe Próspero, que Dios dichosos años guarde, para que goze el mundo las prosperidades que su misterioso nombre promete." Méndez de Silva, Rodrigo, Gloriosa celebridad de España en el feliz nacimiento, y solemnissimo bautismo de su deseado príncipe D. Felipe Próspero, hijo del Gran Monarca D. Felipe IV y de la esclarecida reyna D. Mariana de Austria..., Madrid, 1658, fos 32 r y 32 v.

21 Angiolillo, M., op. cit., p. 67. 
Christi ${ }^{22}$. De cualquier manera, si así fue, nada se sabe al respecto, de forma concreta, que confirme ni desmienta su participación u organización de este tipo de cabalgatas.

La documentación inédita que aquí se presenta, viene a aportar la constancia documental directa de la labor de Antonio María Antonozi en Madrid desde -al menos- comienzos de 1658. El primero de los documentos, fechado en octubre de ese año, hace referencia al libramiento de ciertas cantidades de mejora del sueldo que le correspondía como "Injeniero del [...] buen Retiro". En un inciso conviene destacar también esta última forma de denominar su cargo, pues en ningún momento se le menciona como "Superintendente", sino simplemente como "Ingeniero". Además, da qué pensar sobre el carácter oficial o la existencia efectiva -burocráticamente hablando- del puesto, ya que no ha sido posible la localización de ningún dato sobre su nombramiento oficial -ni el de ninguno de sus predecesores- en la documentación revisada en el Archivo General de Palacio, que no aparece reflejado en las Secciones ni en los Libros de Registros. En cuanto a la cronología, el documento añade que las cantidades que se le libran "son de lo corrido [...] desde primero de Julio deste pressente año de cinquenta y ocho que se le mando el asiento dellos en los libros de la Veheduria y contaduria del dho sitio" 23. Parece que con esa fecha se mejora el salario que Antonozi vendría recibiendo con anterioridad, lo que le sitúa en el cargo en fechas muy próximas a la del fallecimiento de Baccio ${ }^{24}$. Aún así, la documentación continúa sin esclarecer la fecha de su llegada a Madrid, por lo que no es posible descartar ninguna de las dos hipótesis planteadas, tanto la de su llegada junto a Baccio en 1651 como la de su convocatoria para cubrir la vacante dejada por aquel en 1657.

En julio de 1662 Antonozi fue sorprendido por la enfermedad que le costó finalmente la vida, como demuestra el hecho de que no pudo otorgar testamento, sino que redactó una memoria con su firma ológrafa, que se registró ante un escribano de Su Majestad ${ }^{25}$. Mediante ese documento -también inédito y que se presenta ahora- decía descargar su conciencia estableciendo una serie de mandas esenciales, tales como el lugar que escogía como enterramiento en el Hospital de

\footnotetext{
22 Sus datos pudo extraerlos de la obra de Muñoz MoRILlejo, JoAQuín, Escenografía española, Madrid, 1923, en la que se supone la participación de Antonozi en el montaje de este tipo de espectáculos religiosos, p. 25. Sobre el tema genérico de las procesiones del Corpus Christi, cfr. DíEz Borque, J. Ma ., Los espectáculos del Teatro y de la fiesta en el Siglo de Oro español, Madrid, 2002 y también SHERGold, N. D. Y VAREY, J.E., Los autos sacramentales en Madrid en la época de Calderón. 1637-1681. Estudio y documentos, Madrid, 1961, especialmente pp. XIV y XV de la Introducción.

23 El Rey había ordenado la mejora del sueldo de Ingeniero (julio de 1658), permitiendo el libramiento el marqués de Heliche como Alcaide del Real Sitio el 6 de octubre de 1658. Los pagos fueron realizados por don Pedro Vicente de Borja, Regidor de la Villa y Tesorero del Buen Retiro, por mano de Mateo Álvarez, Pagador del Real Sitio, el 18 de octubre de 1658. En esa fecha quedaría inscrito el pago en los libros de la Veeduría y Contaduría del Sitio por Melchor de Alvear y Gamboa, Veedor del Buen Retiro y Alejo de Escalada, Contador de Resultas de Su Majestad. Sobre Melchor de Alvear; sobre estas personalidades de la Administración del Buen Retiro cfr. "Cédula del rey [Felipe IV] nombrando veedor del Buen Retiro a Melchor de Alvear y Gamboa. Madrid, 26 junio 1654" e "Instrucciones dadas a Melchor de Alvear y Gamboa, caballero de Santiago, para el mejor desempeño de su oficio de veedor del Buen Retiro. Sin lugar ni data", Índice de la Colección de don Luis Salazar y Castro de la Real Academia de la Historia, Madrid, 1968, fos 41-42 y 43-45, respectivamente, citado en CUARTERO Y HUERTA, BALTASAR, "Noticias de doscientos trece documentos inéditos sobre el Buen Retiro de Madrid y otros Sitios Reales (años 1612-1661)", en Anales del Instituto de Estudios Madrileños (A.I.E.M.), III (1968), pp. 51-79, cita en p. 53. Sobre Alejo de Escalada, cfr. "Cédula del rey [Felipe IV], nombrando contador del Buen Retiro a Alejo de Escalada, contador de S.M., Madrid, 26 junio 1654", ibídem, fos 47-48. Sobre Pedro Vicente de Borja, cfr. "Cédula del rey [Felipe IV] por la que se nombra tesorero de la Casa y Sitio Real del Buen Retiro a Pedro Vicente de Borja, caballero de Santiago, regidor de Madrid, por renuncia de su padre Sebastián Vicente, regidor de dicha Villa. Madrid, 19 mayo 1649" e "Instrucciones dadas a Pedro Vicente de Borja para el mejor desempeño de su oficio de tesorero del Buen Retiro. Madrid, 19 mayo 1649”, ibídem, fos $62-64$ y $65-67$.

24 Véase el documento $\mathrm{n}^{\mathrm{o}} 1$ del Anexo.

25 Véase el documento ${ }^{\circ} 2$ del Anexo.
} 
los Italianos de Madrid, las misas por su alma, etc. y otorgaba su poder al Auditor apostólico de la Nunciatura, Jacome Fantuci (o Fantuzzi) ${ }^{26}$ para que en su nombre dictase testamento ${ }^{27}$.

En ese documento redactado por poderes se mencionan algunos de sus parientes, y entre ellos dos de sus hermanos, Leopoldo e Innocenzo Antonozzi ${ }^{28}$. En concreto, Antonio María hace referencia a Leopoldo -también nombrado como Leopardo- como su "medio hermano", y le agradece el hecho de haber introducido a otros dos hermanos -suponemos que uno de ellos debió ser Innocenzo- en la Ciudad Eterna ${ }^{29}$. Mediante sus mandas testamentarias, Antonio María favorece a las dos hijas de Innocenzo, legándoles parte de sus alhajas y bienes muebles en Roma, a la par que instituye a su propia madre -a la que no se menciona por su nombre- con el tercio restante de los mismos.

Esta documentación inédita proporciona además cierta idea de sus relaciones sociales en la corte madrileña. En primer lugar aparecen algunos representantes diplomáticos extranjeros, como Juan Bautista Cassano (o Cassani), enviado de los Cantones católicos suizos en Madrid 30 .

También las relaciones con el personal de la Nunciatura parecen bastante fluidas, como se puede deducir de haber nombrado al citado auditor apostólico Jacome Fantuzi como su testamentario.

Del mismo modo, las mandas testamentarias demuestran la proximidad de Antonozi al ámbito del nuncio Monseñor Camillo Massimi (1620-1677) ${ }^{31}$ que ocupó el puesto de Nuncio apostólico en la Corte de España ${ }^{32}$ en 1654 y permaneció en el cargo hasta el 21 de julio de 1658, coincidiendo

\footnotetext{
26 Probablemente el auditor pertenecía a la boloñesa familia Fantuzzi, cuyo palacio en Bolonia fue decorado al fresco por Mitelli y Colonna, antes de que los dos artistas fuesen reclamados por Felipe IV en España. Sobre el Palacio de la Familia Fantuzzi en Bolonia, véase p. ej. Roversi, Giancarlo, Palazzi e case nobili del '500 a Bologna. La storia, le famiglie, le opere d'arte, Bolonia, 1986. Gran cantidad de información inédita muy interesante sobre Jacome Fantuzi contiene el Legajo 3031 de la Sección Estado del Archivo General de Simancas (cartas fechadas desde el 27 de noviembre de 1657 hasta el 28 de abril de 1658, sin foliación), en concreto las cartas solicitando información sobre su persona al embajador español en Roma, duque de Terranova, en el cual se le acusa de afecto a las facciones pro-francesas y de su procedencia de una baja extracción social -en concreto, de ser hijo de un boticario público de Ravena-, información desmentida en cartas posteriores por Gaspar de Sobrellano, agente español en la Corte pontificia, quien dice de Fantuzi a Felipe IV que "...este Auditor es un Ecc[lesiastic $]^{\circ}$ muy Virtuoso Docto y muy afecto a V[uestra] M[ajesta] $]^{\mathrm{d}}$ y a la Naçion [...] no pudiera haver ydo a ese puesto persona mas a proposito..."(22 de abril de 1658)

${ }^{27}$ Lo que ejecutaría el 6 de octubre de 1662. Véase el documento n 3 del Anexo.

28 Parentesco que acierta a señalar BÉNÈZIT, E., Dictionnaire des peintres, sculpteurs, dessinateurs et graveurs et graveurs, vol. I, p. 197 (ad vocem), presentando a los tres hermanos como miniaturistas activos en Roma en los primeros años de la década de los treinta del siglo XVII, cercanos a la Corte pontificia. Cfr. BERTOLOTTI, A., Artisti bolognesi, ferraresi, ed alcuni altri del già Stato Pontificio in Roma nei secoli XV, XVI e XVII, Bolonia, 1886 (reedic. Bolonia, 1968, p. 158). Este último autor no alcanza sin embargo a reconocer el grado de parentesco que une a los tres "miniaturistas".

${ }^{29}$ Leopoldo Antonozzi debió alcanzar cierta fama en Roma como miniaturista y calígrafo, como manifiesta la publicación de su obra De caratteri en Roma, en 1638. Esta obra es un repertorio de motivos caligráficos con un largo elenco de agradecimientos a diversas personalidades de la época pertenecientes o relacionadas con la Curia vaticana.

30 Juan Bautista Cassani fue Tesorero general de la Venerada Cámara apostólica y Embajador por la Serenísima República de Esguízaros católicos; cfr. CALvo, IGnACIO, "La finca madrileña 'Casa-Puerta”, en Revista de la Biblioteca, Archivo y Museo del Ayuntamiento de Madrid, no 3 (1924), pp. 269-285, especialmente p. 276 y también Matilla TASCón, ANTONIO, "Embajadores en Madrid. Franquicia diplomática en el siglo XVII", en Villa de Madrid, no 72 (1981), pp. 61-63, especialemente p. 62.

${ }^{31}$ En el ámbito romano del Cardenal Massimi se menciona a un Giovan Antonio Antonazzi, relacionado con el círculo de Poussin, pero del que se desconoce si le unía alguna relación con Antonio María Antonozi, salvo la parecida forma de sus nombres; cfr. Solinas, FranCESCo, "Poussin et Cassiano dal Pozzo. Notes et documents sur une collaboration amicale", en Nicolás Poussin (1594 - 1665). Actes du colloque organisé au musée du Louvre par le Service Culturel du 19 au 21 octobre 1994, París, 1996, t. I, pp. 289-336, cita en p. 300.

32 StAndRing, Timothy J., "Poussin et le cardinal Massimi d'après les archives Massimo", en Nicolás Poussin (1594 - 1665). Actes du colloque organisé au musée du Louvre par le Service Culturel du 19 au 21 octobre 1994, París, 1996, t. I, pp. 363-392, cita en p. 381. Carpegna, Tommaso di, "Il cardinale Camillo Massimo (1620-1677). Note biografiche attraverso una spigolatura dell'Archivio Massimo", en Camillo Massimo collezionista di antichità. Fonti e materiali, Roma, 1996, pp. 27-44, cita en pp. 31-32.
} 
por tanto en España con Antonozi. Se encargó la administración de la jurisdicción apostólica de la nunciatura a Francesco Mancini, quien aparece mencionado de forma indirecta en la documentación, al referirse un préstamo que uno de los lacayos de éste había realizado a Antonozi.

$\mathrm{Al}$ hilo de ésto último, parece que su vida en la corte española debió desarrollarse sin grandes lujos, como invita a pensar el hecho de que en su estancia madrileña se viese forzado a recurrir en diferentes ocasiones a diversos prestamistas - unos profesionalizados y otros circunstanciales- incluso para hacer frente a los gastos derivados de su delicado estado de salud; lo mismo indican los pocos objetos de valor que se cuentan en su inventario, e incluso el hecho de verse forzado a compartir la propiedad de un carruaje con el benedictino fray Diego de Almeida, predicador de Su Majestad.

Pero uno de los aspectos más interesantes -en lo tocante a su desconocida faceta de pintor- es la referencia de algunos autores a su actividad como miniaturista, extremo que también se ve confirmado por la nueva documentación. Al parecer, tanto él como sus hermanos alcanzaron cierto prestigio en Roma como pintores de miniaturas al servicio de los pontífices. Pues bien, por medio de su testamento, Antonio María dejaba manda expresa para cobrar una miniatura de tema mitológico:

"Assi mismo mando al dicho Don Juan de Carrion todos los libros que yo tubiere y Juntam(en) ${ }^{\text {te }}$ quiero que cobre para si una Ylluminaçion que esta en poder del $P(\mathrm{adr})^{e} r($ (everendo) Julian ferrer Merçenario calçado que es del Sacrifiçio de las ninfas de Diana."33

No se debe pasar adelante -ya que en la cita anterior se hace referencia también a los libros del canónigo- sin comentar algunos de los volúmenes que el ingeniero poseía a su muerte y que se describen en su inventario post-mortem ${ }^{34}$. Los libros que atesoraba en el momento de su fallecimiento no formaban una gran biblioteca, ni están -en apariencia- especialmente relacionados con su actividad profesional. Pero un análisis detenido demuestra más bien todo lo contrario y, sobre todo, la amplitud de su formación, por lo que la descripción de algunos de estos volúmenes no es gratuita.

No sorprende que una buena parte de los ejemplares que Antonozi reunió versasen sobre cuestiones piadosas, como el "Rezo Romano", el "Nuevo Testamento", "Oficios de Semana Santa", "Preparación de Sacerdotes", entre otros, dada su condición de eclesiástico. Entre las lecturas relativas a temas religiosos o más bien piadosos, encontramos registrado un título como es "la Dama beata compuesto por Joseph Camerino" 35 , cuyo autor está directamente relacionado con la Nunciatura madrileña. Tenía lecturas edificantes, tales como biografías ejemplarizantes, por ejemplo "vida del Pe Marzelo Mastrilli de la Compañía de Jesús"36 o "Vida de Pio quinto". Resulta curiosa su afición a los juegos de estrategia, como manifiestan diversos ejemplares, tales como "....un libro en italiano del Juego del ajedrez ...", así como otros dos volúmenes sobre el "Juego de Damas", amén de las "treinta pieças blancas y negras del Juego de ajedrez" que

33 Anexo, documento $\mathrm{n}^{\mathrm{o}} 2$

34 Anexo, documento $\mathrm{n}^{\mathrm{o}} 4$.

35 La Dama beata, compuesta por Ioseph Camerino, Procurador de los Reales Consejos, Notario y Secretario de Breves y Comisiones Apostólicas en el Tribunal de la Nunciatura de Su Santidad. Dedicada al Excelentissimo Señor Don Ramiro Felipez de Guzman, Señor de la Casa de Guzman, Duque de Sanlucar, de Medina de las Torres, etc., Madrid, por Pablo del Val, año de 1655.

36 Al jesuita Marcelo Mastrilli se le relaciona con un milagro obrado por San Francisco Javier, en 1633, cuando el joven jesuita Mastrilli sufrió un mortal accidente durante unas obras en la capilla Vicerreal de Nápoles, en el que salvó la vida por intercesión del santo español, al que había prometido consagrarse al ejercicio del apostolado en las Indias orientales. Es uno de los denominados mártires de Japón, junto al padre Antonio Capece, etc., con quienes había partido desde Lisboa rumbo a las misiones asiáticas. El también jesuita Juan Eusebio Nieremberg fue el autor de otra obra, también laudatoria de la vida de Mastrilli, titulada Honor del gran Patriarca san Ignacio de Loyola, fundador de la Compañía de Iesus, En que se propone su vida, y la de su Dicipulo el Apostol de Las Indias S. Francisco Xavier. Con la milagrosa Historia del admirable Padre Marcello Mastrilli, y las noticias de gran multitud de Hijos del mismo S. Ignacio, varones clarissimos en santidad, dotrina, trabajos y obras maravillosas en servicio de la Iglesia, Madrid, María de Quiñones, 1645. 
también recoge el inventario de bienes. Son varios los títulos que atestiguan su cultura clásica latina, por ejemplo "Terençio latino comentada en lengua toscana", "la Eneyda de Virjilio" o "los metamorphosios de Ovidio", que seguramente -sobre todo ésta última- sirvieron de referencia para la dirección escénica de algunas de las obras mitológicas de Calderón. Sin embargo, más llamativa, también por curiosa teniendo en cuenta su condición, es la presencia en el elenco librario de títulos como el "Laberinto de Amor" de Giovanni Bocaccio. Además, se cuentan también otras obras de la literatura moderna italiana de gran difusión en la época como las "Rimas del Torquato Tasso". Como puede apreciarse, no sólo la prosa, sino también la poesía de todos los tiempos, estaba representada entre sus libros, con ejemplares de "Ars poetica española", "Triumpho de la paz en verso latino", y "Ragguagli de Parnaso en Italiano".

Su multidisciplinar formación se complementaba con obras como "Otro libro Intitulado Arte de Ynjenio" 37 o bien "la Hist de Europa", e incluso algún título como "la Rebolucion de Napoles", en referencia a la todavía por entonces reciente revuelta napolitana, liderada por Massaniello -obra, suponemos, escrita en tono laudatorio de la intervención regia- que versaban sobre Política, como "espejo politico y moral de principes y ministros de españa" 38 , que nos hace recordar las teorías de Neumeister sobre la escena como autorrepresentación del monarca-espejo del Estado ${ }^{39}$, acercándonos aún más al concepto cósmico de la escena teatral en el Barroco.

Muy significativa de su labor en España es la posesión de "otro libro Intitulado Triumphos de Amor y Fortuna", del que tenía dos ediciones diferentes, pues también se registra otra entrada como "Triumphos de Amor y fortuna con saynetes y loas". Se trata de la comedia escrita por Antonio de Solís que Antonozi tuvo la oportunidad de poner en escena en el Buen Retiro en 1658. Y no es el anterior el único ejemplo de comedias de autores españoles, pues también se encuentra "Una comedia de los dos Amantes del cielo" -que, a pesar de no hacerse expreso en el inventario, se refiere a la obra del mismo título de Pedro Calderón de la Barca-, "el capuchino escocés" 40 de Félix Lope de Vega y otra bajo el título de "Restauraçion de España"41, entre otras no identificables, bajo los epígrafes de "otro libro Viejo de comedias desquadernado", "Tres libros de Comedias de diferentes autores" y "Otro libro de Comedia Italiana".

Además conservó "dos libros de musica", suponemos que por la relación de la materia con los despliegues escénicos cortesanos y quizá otro tanto por conocimientos o por afición.

No faltan ejemplares sobre ingeniería, materia que le permitió el acceso a su cargo en el Buen Retiro, en sus diferentes aspectos, desde la mecánica hasta la hidráulica. Así, en algunas de las entradas se lee: "Un libro Italiano Intitulado Espiritiali de Hieroni Alexandrino" 42 y también "del mismo Alexandrino de li gli automati"43. Estas dos obras nos recuerdan que Lope de Vega

37 Podría tratarse quizá de Agudeza y arte de ingenio, de Baltasar "Lorenzo" Gracián.

38 Debe tratarse de la obra Espejo político y moral para príncipes y ministros y todo género de personas, compuesto por el célebre autor persa Bidpai, que fue traducido al castellano por el raguseo Vincenzo Brattuti, del cual se realizaron varias ediciones en Madrid, como las de Domingo García y Morrás, en 1654 o la de José Fernández Buendía, en 1658.

39 NeUMEISTER, S., op. cit., , véase p. 153.

40 Podría suponerse que se trata de la obra de este título escrita por Félix Lope de Vega, aunque también existe una obra homónima, escrita en lengua toscana por el arzobispo de Fermo, Giovanni Battista Rinuccini y traducida al castellano por Antonio Vázquez, con varias ediciones madrileñas, como la de Gregorio Rodíguez en 1447 o la de Diego Díaz de la Carrera en 1661.

${ }^{41}$ Comedia burlesca cuya autoría se atribuye a Monserer Solís y don Diego de Silva y que fue representada ante los reyes en el Buen Retiro la velada de San Juan del año 1655; cfr. MuÑoz MoRILlejo, J., op. cit., p. 35; sin embargo, Mesonero Romanos le atribuye una obra del mismo título a Juan Vélez; Mesonero Romanos, Ramón, Dramáticos posteriores a Lope de Vega, B.A.E., II, Madrid, 1951.

42 Spiritiali di Herone Alessandrino / Ridotti in lingua volgare da Alessandro Giorgi da Urbino, Urbino, 1592.

43 Di Herone...De gli automati overo machine se movementi... / tradotti dal greco da Bernardino Baldi, abbate di Guastalla, Venecia, 1589. 
llegó a llamar a Lotti el "Nuevo Hierón de Alejandría" y apreciaba que el florentino no era "menos admirable en sus máquinas que aquel insigne griego". En el caso de los autómatas, nos viene a la memoria la anécdota señalada por Prieto González que recogía Vicente Carducho sobre una ocasión en la que Lotti había construido la cabeza de un Sátiro "que con movimiento feroz mueve los ojos, orejas y cabellos, y abre la boca con tanta fuerza y ronquido que espanta y asombra a cualquiera que no esté sobre aviso" 44 .

Precisamente, por su labor creadora de tramoyas, mutaciones y artificios escenográficos se le supone conocedor de los rudimentos de la Arquitectura, y no es raro hallar entre sus pertenencias el "libro de la Arquitectura de Andrea Paladio con diversas figuras y traças de pintura"45. Pero lo más sorprendente es encontrar entre sus volúmenes "Un libro grande Freggi del Arquitectura con diferentes figuras dedicado a Agustino Miteli Pintor" 46 . El encontrar una referencia sobre un posible contacto entre Antonozi y el fresquista boloñés parece un aspecto importante, cuya precisión y justa medida habrá que encomendar a futuras investigaciones.

Entre las pertenencias inventariadas no consta precisamente una gran colección de dibujos puesto que -además del mentado recopilatorio de motivos arquitectónicos- sólo se incluyen dos referencias, "Un papel grande en que esta dibujada una selba" y "Un carton do ay diferentes dibujos", que pudieran interpretarse como trazas o esbozos de escenografías, sobre todo el primero, con la referencia a una selva amena, en la que quizá pudieron desarrollarse las acciones calderonianas.

Como curiosidad habría que destacar la aparición en el elenco de bienes de una "figura de escultura de madera pequeña que los miembros de ella se andan y juegan alterno", o sea de un muñeco articulado, probablemente un modelo de proporciones para dibujo o para un autómata, sobre los que se interesaba en sus lecturas.

Del inventario también puede deducirse la dedicación efectiva de Antonozi al ejercicio de la pintura a través del registro de diversos artilugios y herramientas para este uso, tales como piedras de moler pigmentos y una cajita para guardar los pinceles y colores.

\footnotetext{
44 Carducho, Vicente, Diálogos de la Pintura (su defensa, origen, esencia, definición, modos y diferencias), Madrid, 1979, nota 98, p. 249, citado por Prieto GonZÁlez, José Manuel, "Las Artes Plásticas...”, en Espacio, Tiempo y Forma, serie VII, t. 13 (2000), pp. 173-219, cita en p. 209.

45 I quattro libri dell'Architettura...de Andrea Palladio.

46 Aunque los datos son escasos, parece tratarse de un repertorio de imágenes o "freggi" extraídos de motivos arquitectónicos o realizados para la decoración arquitectónica que servirían como referencia de taller. Lo que sorprende en este caso no es tanto que Antonozi estuviese en posesión de uno de estos álbumes, como que éste estuviese dedicado nada menos que al pintor fresquista boloñés Agostino Mitelli. Sin embargo, este detalle no deja muy claro si la recopilación de modelos era obra de Antonozi y que éste le dedica la obra a Mitelli o si por el contrario pudiera haber sido una obra de un tercer autor dedicada al boloñés. Giuseppe María Mitelli, hijo del pintor, recordaba los materiales y repertorios que su padre había dejado en España al morir en 1660 -también recordado por Passeri, Giambattista, Vitte de'pittori, scultori ed architetti che hanno lavorato in Roma morti dal 1641 fino al 1673, Roma, 1772, p. 273-, llegando incluso a acusar a Dionisio Mantuano de haberse apropiado de ellos de forma ilícita (este aspecto se trató más pormenorizadamente en García Cueto, David y SÁnchez del Peral y López, Juan Ramón, "Dionisio Mantuano: Venturas y desventuras de un pintor boloñés en las Cortes de Felipe IV y Carlos II", en Actas del I Coloquio Internacional 'Los extranjeros en la España Moderna', Málaga, noviembre 2002, pp. 227-240); también en Sánchez del Peral y López, J. R. y García Cueto, D., "Dionisio Mantuano, un artista en las cortes de Felipe IV y Carlos II. Más allá de 'el mas unico que se conoce en estos reynos en el arte de pintar al fresco'”, en VV. AA., España y Bolonia. Siete siglos de relaciones artísticas y culturales, Madrid, 2006, pp.-263-278, cita en p. 269. ¿Pudieron de esta forma llegar algunas de estas herramientas de Mitelli a manos de Antonozi por un conducto indeterminado? La alternativa se fundamentaría en que Antonozi hubiera tenido contacto directo con Mitelli y Colonna, mientras que los boloñeses realizaban sus decoraciones pictóricas en el Buen Retiro hacia 1659. También PASSERI, G., op. cit., p. 272, recuerda en la biografía que dedica a Mitelli que los dos fresquistas llegaron a Madrid, en parte por las pesquisas diplomáticas del cardenal Giovan Carlo de' Medici, quien como queda referido, se implicó en la búsqueda -infructuosa- de un sucesor para el cargo vacante por la muerte de Antonozi. Quizá el purpurado estuviese -de algún modo que ignoramos- detrás de las relaciones entre estos artistas.
} 
Tras la revisión de sus bienes se entiende aún mejor la necesidad de la intervención del romano en las mises en scène pretendidas por Felipe IV, puesto que los ingenieros italianos -y me permito ahora parafrasear a Prieto González- "evidenciaban una capacidad artística que abarcaba numerosos campos, desde la arquitectura hasta el diseño de vestuario pasando por la ingeniería, la óptica-perspectiva, el grabado, la jardinería, la pintura...; su labor se centraría en el diseño de tramoyas y decorados en perspectiva más que en la materialización de los mismos". En definitiva, Antonozi representó al homo universalis al que se refirieron Neumeister y Tintelnot.

$\mathrm{Al}$ hilo de lo anterior, parece necesario insistir en ciertas cuestiones de fondo, que requieren una aclaración. Y es que algunos autores señalan la convivencia de los "escenógrafos" españoles -Francisco Ricci, José Caudí, Francisco de Herrera, etc.- con los italianos, como Dionisio Mantuano y, por supuesto, Antonozi ${ }^{47}$. Efectivamente, todos estos artistas trabajaron conjuntamente en los montajes escénicos de las comedias del Buen Retiro, pero hay que distinguir entre "ingenieros tramoyistas" y "pintores de tramoyas" -como muy acertadamente se indicó en su momento ${ }^{48}$, y el hecho de que los primeros sí podían ser lo segundo, pero no siempre se podía dar la circunstancia inversa. Los españoles, en líneas generales, no tenían formación en ingeniería como para diseñar mutaciones al estilo italiano ${ }^{49}$, de ahí que se hiciese venir a especialistas italianos -sobre todo toscanos, como Fontana, Lotti o Del Bianco- hasta bien entrada la segunda mitad de la centuria. Si tras la muerte de Antonozi no se mandó a ningún ingeniero nuevo desde Florencia, no fue porque no interesase, sino -como prueban documentos ya reseñados- porque no se consiguió encontrar a nadie con la suficiente cualificación para esta tarea y, quizá en cierta medida, por la decadencia del Estado -a esas alturas difícilmente enmascarable-y lo alcanzado de la Hacienda, que hacía imposible el mantenimiento del tren de gastos del reinado anterior.

\footnotetext{
47 "Sucesor de Loti en la corte madrileña fue el también florentino Baccio del Bianco, llamado en 1651 por Felipe IV para sustituir a aquel. Junto a éstos y otros italianos, como Antonozzi Romano y Dionisio Mantuano, desempeñaron el papel de escenógrafos reales pintores españoles como Francisco Ricci, Francisco de Herrera el Mozo, Francisco Ignacio Ruiz de la Iglesia, Teodoro Ardemans y Antonio Palomino.", RodRíGuez G. DE CEBALlos, A., "Escenografía y tramoya en el teatro español del siglo XVII", en EGIDO, A. pp. 33-60, cita en p.44; “...Su muerte [de Baccio del Bianco] en 1657 abre un nuevo periodo en que intervienen los escenógrafos Francisco Rizzi y Antonio María Antonozzi”, PEDRAZA JIMÉNEZ, F.B., op. cit., cita en p. 84.

48 “...existe una radical diferencia entre el ingeniero director o inventor de los dispositivos de la escena, y suministrador, sin duda, de diseños y bocetos, y la de los ejecutores, pintores con frecuencia secundarios en el panorama artístico cortesano [...] El Director había de dar trazas y tramoyas, es decir, todo el aparato escénico con las soluciones mecánicas imprescindibles para las mutaciones, y los pintores habían de ejecutar los paramentos, al temple generalmente, sobre lienzos de grandes dimensiones (telones y forillos), así como los elementos corpóreos (máscaras, accesorios, trajes pintados) necesarios para la acción”, PéREZ SÁNCHEZ, A. E., op. cit., cita en p. 62. A pesar de este preciso discernimiento, el propio autor cae en el error de seguir confundiendo los términos, inducido por las noticias de Palomino, especialmente en el caso de Francisco Rizi, que comentamos más abajo.

49 Esta teoría podría ilustrarla el relato acerca de Francisco Rizi que Palomino incluye en la biografía que dedica a José Antolínez: "Pintábase en aquel tiempo mucho al temple, para las mutaciones de las comedias célebres, que se hacían a Sus Majestades en el Buen Retiro: y como Antolínez no concurría a estas funciones, despreciábalas; llamando pintores de paramentos, a los que las ejecutaban. Súpolo Rizi, que las gobernaba entonces de orden del Rey; y en una prisa, que se ofreció, dispuso, que un Alcalde de Corte le notificase, pena de cien ducados, fuese a pintar al Retiro. Fue el dicho Antolínez, y habiéndole dado Rizi a pintar un lienzo al temple, mandando que nadie le advirtiese nada; estuvo todo el día Antolínez haciendo y deshaciendo, sin entrar, ni salir; al cabo de lo cual le dijo Rizi: ¿Ve aquí vuesa merced lo que es pintar paramentos?..."; PALOMino, AnTonio, Vidas, (Ayala, Nina, ed., Madrid, 1986, pp. 243-245, cita en p. 244). Toda esta historia parece apoyar la teoría de que la escena va ganando en lo que podríamos llamar "plasticidad", al encomendarse los decorados a reputados pintores, pero que debieron ir perdiendo en grandilocuencia técnica, ante la desaparición de los ingenieros de la "Superintendencia". La mencionada técnica de decoración pictórica al temple que requerían los decorados escénicos, parece refrendar lo anteriormente expuesto, en el sentido de que se pasa a encomendar dicha labor a pintores con experiencia como fresquistas, versados por tanto en la técnica al temple.
} 
Como queda dicho, el relevo de los italianos por los españoles en este contexto no fue ni inmediato ni "natural" y la documentación aportada aquí nos permite puntualizar afirmaciones como la de algún autor al decir:

"Heredero de las habilidades de Loti, Bianco será el ingeniero director de las tramoyas hasta su fallecimiento en 1657. A partir de esa fecha, parece que es el español, hijo de italiano, Francisco Rizi, quien asume por entero la responsabilidad de la dirección de los teatros de la Corte, especialmente del Buen Retiro, en calidad de ingeniero director. Luego serán sus discípulos y sucesores quienes lo ocupen hasta el cambio de siglo "50.

Obviamente, tanto Rizi como sus sucesores, Herrera el Mozo, Juan Fernández de Laredo, Vicente de Benavides, José Caudí, Francisco Ignacio Ruiz de la Iglesia, etc., no hacen sino pintar perspectivas y telones bajo la supervisión de quien verdaderamente era el director de las representaciones.

De cualquier modo, en el momento de la muerte de Antonozi, las representaciones teatrales en el Buen Retiro habían sido suspendidas. La afrenta sufrida por el marqués de Heliche y del Carpio, al ser relevado del cargo de Alcaide del Real Sitio en beneficio de su poco estimado primo, el duque de Medina de las Torres, desembocó en un episodio que en su época fue interpretado como un conato regicida, y que tuvo como escenario -nunca mejor dicho- el Coliseo de las Comedias. Este suceso provocó que se suspendiesen las Comedias en el Buen Retiro desde el 19 de enero de 1662 hasta comienzos de 1670, avanzada ya la regencia de Mariana de Austria ${ }^{51}$.

Antonio María Antonozi fue el último de los grandes ingenieros que ostentaron la oficiosa Superintendencia de las Comedias del Buen Retiro en el reinado de Felipe IV. Tras su prematura muerte -motivo que sin duda le ha hecho permanecer sepultado en el olvido- se produce, como ya se ha mencionado, un marasmo en las representaciones teatrales, hasta algunas décadas después, cuando, ya en el reinado de Carlos II, se reanuda la actividad teatral cortesana. Pero ya por entonces, la forma de las puestas en escena debía de haber cambiado de carácter, limitándose a lo pictórico de los decorados, lo cual permitía tomar mayor protagonismo a los españoles. Y eso a pesar de la permanencia en la Corte de Dionisio Mantuano ${ }^{52}$, ingeniero de formación -con

50 Pérez Sánchez, A. E., op. cit., cita en p. 63. Prosigue con el ejemplo de Francisco Rizi y añade que fue “...a la desaparición de Baccio del Bianco en 1656 [sic.], el verdadero director e ingeniero de las tramoyas del Buen Retiro al menos hasta la muerte de Felipe IV en 1665". Se fundamenta en las afirmaciones de Palomino al decir "que tuvo Rizi muchos años a su cargo la dirección de los teatros de mutaciones en las comedias que se hacían entonces, con gran frecuencia, en el Retiro a sus Magestades; en cuyo tiempo sirvió mucho e hizo grandes trazas de mutaciones porque era grandísimo arquitecto y perspectivo". Que fuese un gran tracista o arquitecto no se le niega, pero otra cosa es que tuviese capacidad para dirigir una puesta en escena y desde luego, no tenía la formación en ingeniería para crear las mutaciones al uso. Añade Pérez Sánchez el dato de un memorial que Rizi dirige en 1673 a Carlos II en el que decía "asegurar no haber visto $\mathrm{V}^{\mathrm{a}}$ Magestad en dicho tiempo fiesta de Theatro que no aya sido de su mano". Obviamente el pintor exagera o no ha sido bien interpretado, pues podría referirse sólo a la obra de pintura.

${ }^{51}$ Las comedias siguieron representándose en el Alcázar hasta que "en 1665, con motivo de la muerte de Felipe IV, su viuda vuelve a prohibirlas "hasta que su hijo pudiese gustar de ellas"”; CARILla, E., El Teatro español en la Edad de Oro. Escenarios y representaciones, Buenos Aires, 1968, p. 75. En enero de 1670 se celebra en el Buen Retiro la representación de Fieras afemina amor, de Pedro Calderón de la Barca y hasta el 6 de noviembre de 1672, no se representaría en el Alcázar nuevamente, con la puesta en escena de Los celos hacen estrellas, de Juan Vélez de Guevara.

52 Zapata Fernández le menciona como director de escena ya durante el reinado de Carlos II, pero está claro que las arcas reales no se podían permitir los excesos del reinado de Felipe IV y que quizá la forma de representar la Majestad Real a través de la escena se desecha a favor de otros tipos de representación y que las preocupaciones del último Habsburgo eran distintas a las del reinado de su progenitor; cfr. ZAPATA FERnÁndeZ dE la Hoz, Mª Teresa, La entrada en la Corte de la reina $M^{a}$ Luisa de Orleans. Arte y fiesta en el Madrid de Carlos II, Madrid, 2000, p. 232. 
experiencia en cuestiones hidráulicas y de fontanería- además de pintor fresquista, que seguramente hubiera sido capaz de retomar -aunque hay que reconocer que probablemente no hubiese igualado a Lotti- la artificiosidad de las puestas en escena del real sitio madrileño ${ }^{53}$.

\section{ANEXO DOCUMENTAL 54}

DOCUMENTO 1. Archivo Histórico de Protocolos de Madrid (A. H. P. M.), Protocolo 10138, varias foliaciones, (18 / 10 / 1658)

"Carta de pago que otorgo el canonigo Don Antonio Maria Antonozio [...] confesso haver recibido [...] quatro mil y quinientos Reales de Vellon [...] por libram ${ }^{\text {to }}$ del [...] Marques de Eliche [...] por los que le an consignado a razon de çien escudos de plata al mes que Su Magestad le mando acrecentar por la paga del sueldo de Injeniero del dho buen Retiro $[\ldots] "$

DOCUMENTO 2. A. H. P. M., Protocolo 10138, v. f., (27 / 09 / 1662)

"Memoria de lo que debo yo Don Antonio Maria Antonoçi y me deben hasta oy 29 de jullio de 1662 años $=y$ [...] declaraçion de la forma en que quiero se haga mi testamento y Ultima Voluntad [...] sea en la Conformidad que dispusiere el $s^{r}$ Auditor del $s^{r}$ Nunçio a quien he dado poder para haçer mi testamento= // Y quiero y es mi Voluntad que se este a esta memoria Como si fuera escritura hecha ante Escribano por si la gravedad de mi enfermedad no me da lugar a haçer testamento en forma y lo firme en Madrid a Veinte y nuebe de jullio de mill seisçientos y sesenta y dos años"

DOCUMENTO 3. A. H. P. M., Protocolo 10138, v. f. , (06 / 10 / 1662)

"Testam to En Virtud de Poder [...] Don Jacobo Elephantuçio Ravena Abbad de san Leonardo protonotario Aplico y Auditor gral de la Nunçiatura de estos Reinos de España [...] por Virtud del Poder para Testar que Don Antonio Maria Antonoçio Clerigo presvitero otorgo [...]"

DOCUMENTO 4. A. H. P. M., Protocolo 10138, v. f., ( 07 / 11 / 1662)

"Inbentario por el sor Auditor de España Don Jacome elephantuçio Abbad de S Leonardo. [...] testamentario Insolidun del canonigo $D^{n}$ Antonio Maria Antonoçio Ya Difunto [...]"

su poco estimado primo, el duque de Medina de las Torres, desembocó en un episodio que en su época fue interpretado como un conato regicida, y que tuvo como escenario -nunca mejor dicho- el Coliseo de las Comedias. Este suceso provocó que se suspendiesen las Comedias en el Buen

Recibibo: 8-III-2004 Aceptado: 7-VI-2004

53 En Madrid también encontramos en activo a Cosme Lotti, "El Joven", también formado como ingeniero, pero implicado en obras hidráulicas de más modesta condición y en propuestas no siempre atendidas, al chocar con la precariedad de las arcas reales. Archivo General de Simancas, Casa y Sitios Reales, Leg. 318, fo 477-480 (año 1688).

${ }^{54}$ La documentación se presenta en extracto por condicionante de las normas estilísticas de la revista. Los párrafos extractados han sido transcritos de manera literal, sin alterar la gramática ni ortografía originales del documento, manteniéndose las abreviaturas sin desarrollar. Los puntos y aparte se indican por medio de dos barras ( // ). Debido a dichas exigencias estilísticas se han eliminado ciertos párrafos intermedios indicados mediante corchetes y puntos suspensivos ( [...] $)$. 